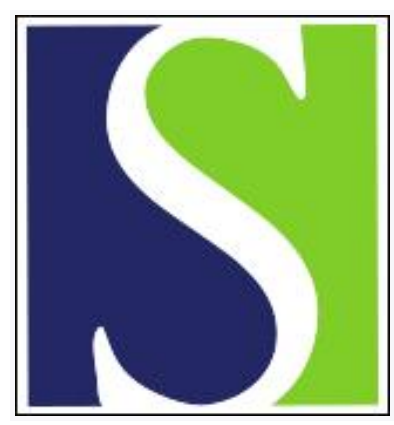

Scand J Work Environ Health 2000;26(4):283-291

https://doi.org/10.5271/sjweh.544

Issue date: Aug 2000

Shoulder disorders and postural stress in automobile assembly work

by Punnett L, Fine LJ, Keyserling WM, Herrin GD, Chaffin DB

The following articles refer to this text: 2001;27(1):82-83;

2002;28(5):289-292; 2009;35(2):113-126; 2010;36(3):185-187

Key terms: automobile assembly work; biomechanics; ergonomics; job analysis method; MSD; musculoskeletal disorder; postural stress; posture; repetitive work; shoulder disorder; shoulder tendonitis; video recording

This article in PubMed: www.ncbi.nlm.nih.gov/pubmed/10994793

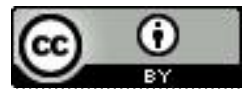




\title{
Shoulder disorders and postural stress in automobile assembly work
}

\author{
by Laura Punnett, ScD, ${ }^{1,2}$ Lawrence J Fine, MD, , 3 W Monroe Keyserling, PhD, ${ }^{1}$ Gary D Herrin, PhD, ${ }^{\dagger}$ Don \\ $B$ Chaffin, $P h D^{\prime}$
}

Punnett L, Fine LJ, Keyserling WM, Herrin GD, Chaffin DB. Shoulder disorders and postural stress in automobile assembly work. Scand J Work Environ Health 2000;26(4):283-291.

\begin{abstract}
Objectives A case-referent study was conducted in an automobile assembly plant to evaluate the risk of shoulder disorders associated with nonneutral postures.

Methods The cases were workers who reported shoulder pain to the plant clinic during a 10-month period and met symptom criteria (pain frequency or duration in the past year) in an interview; more than one-half also had positive findings in a physical examination. The referents were randomly selected workers who were free of shoulder disorders according to the clinic records, the interview, and the physical examination. For each of the 79 cases and 124 referents, 1 job was analyzed for postural and biomechanical demands by an analyst blinded to the casereferent status.

Results Forty-one percent of the subjects flexed or abducted the right arm "severely" (above 90 degrees) during the job cycle, and 35\% did so with the left arm. The peak torques at the shoulder were rather low. Shoulder disorders were associated with severe flexion or abduction of the left [odds ratio (OR) 3.2,95\% confidence interval $(95 \% \mathrm{CI}) 1.5-6.5$ ] and the right (OR 2.3, 95\% CI 1.2-4.8) shoulder. The risk increased as the proportion of the work cycle exposed increased. The relationships were similar for the cases with and without physical findings. Use of hand-held tools increased the risk and also modified the association with postural stress, although the joint exposure distributions limited full analysis of this finding.

Conclusions The findings support the conclusion that severe shoulder flexion or abduction, especially for $10 \%$ or more of the work cycle, is predictive of chronic or recurrent shoulder disorders.
\end{abstract}

Key terms biomechanics, ergonomics, job analysis methods, musculoskeletal disorders, posture, repetitive work, shoulder tendonitis, video recording.

Musculoskeletal disorders affecting the shoulder have been the subject of much investigation in the Nordic countries but less so in the United States, especially when compared with back and wrist or hand disorders. The hypothesis that repetitive arm movements and sustained elevation of the arm strain the soft tissues of the shoulder region has high plausibility in light of the laboratory evidence. Biomechanical studies have shown that shortterm effects such as fatigue, increased electrical muscular activity, and transient soft-tissue discomfort result from work in nonneutral shoulder postures (1-4). Some epidemiologic research has examined the relationship of shoulder "injury" or chronic musculoskeletal pain with respect to these same postural stresses $(3,5)$; a recent review by the National Institute for Occupational Safety and Health in the United States concluded that there was epidemiologic evidence of a causal relationship for repetitive work and for nonneutral postures but that the literature was limited on both points (6).

The specific objectives of this study were to apply a standardized observational method to evaluate the postural demands on the shoulder in selected automobile assembly operations, to characterize the physical examination findings and the costs of shoulder disorders in these jobs, and to compare the occupational exposures of workers with and without shoulder disorders.

1 Center for Ergonomics, The University of Michigan, Ann Arbor, Michigan, United States.

2 Currently with the Department of Work Environment, University of Massachusetts Lowell, Lowell, Massachusetts, United States.

3 Currently with the Division of Surveillance, Hazard Evaluation and Field Studies, National Institute of Occupational Safety and Health, Cincinnati, Ohio, United States.

Reprint requests to: Dr L Punnett, Department of Work Environment, University of Massachusetts Lowell, One University Avenue, Lowell MA 01854, USA. [E-mail: Laura_Punnett@UML.EDU] 


\section{Subjects and Methods}

\section{Study population, morbidity and cost data}

A case-referent study was conducted in an automobile assembly plant employing approximately 1335 workers (monthly average payroll) in 4 major production departments (body, chassis, paint, and trim). The cases were identified prospectively over a 10 -month period from the workers who reported to the plant medical department with neck or shoulder complaints, excluding repeat visits within 90 days. Potential referents were selected randomly from the rosters of the 4 production departments at the beginning of the study, excluding workers who had reported any back, neck, or shoulder injury within the 90 days preceding the interview date or since the start of data collection, whichever was earlier.

Each study subject was interviewed with a standardized questionnaire that covered demographics, work history, medical history, and nonoccupational activities. Each subject also received a physical examination of the shoulder, consisting of 5 active-passive and 4 resisted motions (7). The worker was asked to rate discomfort during any motion from 1 (very mild) to 8 (very severe). The maneuver was considered positive if the discomfort rating was 3 or higher; for the resisted motions a finding of reduced strength (below 4 on a scale from $1-5$ ) was also required.

The final case definition was a shoulder disorder reported to the plant medical department during the study period and a history, reported in the interview, of shoulder pain on more than 3 occasions, or for more than 1 week, during the last year. The cases were subdivided by whether or not they had positive findings during at least 1 maneuver in the physical examination of the shoulders. The referents were defined as the workers with no medical report for a back, neck, or shoulder disorder during the study period, no episode of back or shoulder pain in the last year of the interview, and normal status for range of motion in a physical examination of the back, neck, and shoulders.

A total of 104 potential shoulder cases and 310 potential referents were identified from the reports to the medical area and the department rosters, respectively. Ninety-three potential cases ( $89 \%$ ) and 259 potential referents $(84 \%)$ were successfully interviewed and examined. Seventy-nine $(85 \%)$ of the 93 medical reports met the study case definition for a shoulder disorder (ie, in the interview they reported at least 1 episode of pain in the previous year on at least 3 occasions or for at least 1 week. Among the 259 potential referents, only 125 workers were free of back, neck, or shoulder pain according to the interview and physical examination. The job of 1 referent was not evaluated; therefore 124 referents were available for the analysis. The same 124 subjects had served as referents in a parallel, previously reported case-referent study of back disorders (8).

Only 4 of the 203 final study subjects were women. The mean age of the shoulder cases was 39 (SD 8) years and that of the referents was 41 (SD 9) years (population range 29-64 years). The 2 groups had been employed at the plant for approximately the same length of time (referents 11.0 years, cases 9.2 years), but the referents had been employed in their current jobs slightly longer (5.1 years) than the cases (3.6 years).

Data collected from the medical records and interviews were used to estimate some of the costs of the shoulder disorders reported to the plant medical department. The medical records covered in-plant care for the current episode, as defined administratively. The standardized interviews provided information on days lost from work in the previous year, work restrictions, and transfers from jobs that were perceived to aggravate pain. Data were not available on other medical care, workers' compensation claims or payments, future costs, or "indirect" costs to the employer such as decreases in productivity or quality or increases in medical insurance premiums. The estimated costs to the plant included medical visits and treatments, lost worktime, work restrictions, and voluntary bid-offs ${ }^{4}$ from jobs that aggravated shoulder pain. Based on information obtained from company personnel, the following assumptions were made in calculating these costs: (i) each in-plant medical visit or treatment cost USD 50, on the average, (ii) each work absence of more than 5 days resulted in training of 1 replacement worker, who also cost USD 295 per week in replacement labor (not covered by worker's compensation), (iii) one-half of all work restrictions resulted in the training of replacement workers, (iv) each job transfer resulted (conservatively) in training for both the injured worker and the worker replacing him or her on their new jobs, and ( $v$ ) the cost of training a replacement worker on a new job was 16 hours of training (on work time) at an average wage of USD 23 per hour, or USD 368.

\section{Ergonomic job analysis}

One job was selected for analysis for each subject. For the cases, the preferred "study job" was the 1 reported to be held at the time of the onset of the current episode of pain, if it was still performed in the plant. If not, the job associated with the aggravation of pain was identified as the study job. For all the referents, the study job was the

Workers in this facility could bid for better jobs based on their union seniority. (A better job might involve higher wages or better work conditions such as lower physical demands.) A worker experiencing shoulder pain could "bid-off" to a less-physically-demanding job, provided that he or she had sufficient seniority. 
current job. For subjects who would not or could not be videotaped performing their own jobs, permission to videotape was requested of another, "proxy" worker (ie, the person found to be performing the study job in the subject's absence). Fifty-eight (29\%) of the 203 subjects were not videotaped performing their own jobs; thus, for $34(43 \%)$ of the cases and $24(19 \%)$ of the referents, it was necessary to substitute analyses of proxy workers.

For each job, 1 work cycle deemed to represent the typical job demands, after observation of several cycles, was selected and videotaped. The videotape was reviewed in the laboratory and analyzed for shoulder postures using a "simulated real time" postural analysis software system (9). Shoulder postures on each side were categorized as neutral ( $<45$ degrees included angle from the trunk), mild flexion or abduction (46-90 degrees), or severe flexion or abduction ( $>90$ degrees) (figure 1 ). The summary statistics generated for each job included the total duration of each posture, as a percentage of the work cycle, and the frequency per cycle of each posture, both computed for the left and right shoulders separately.

In each job with a load of at least 44.5 newtons ( 10 pounds) held in the hands, up to 9 loaded postures were selected for an analysis of biomechanical demands. The peak reactive shoulder torques in 3 planes were estimated using a 3-dimensional biomechanical strength model (10). For jobs that did not involve lifting of at least 44.5 newtons, the peak biomechanical forces were estimated for the posture required by the job that deviated the most severely from neutral. The analyst also recorded whether or not the job involved use of at least 1 hand-held or suspended power tool.

\section{Statistical methods}

The cases and referents were compared with respect to exposures in the study job to nonneutral postures, peak biomechanical torque at the shoulders, and use of a handheld power tool. Continuous variables were compared with the Student t-test, if normally distributed, with equal or unequal variances as indicated by the F statistic (11); the Wilcoxon rank sum test for nonparametric comparisons was used for continuous variables with non-Gaussian distributions (12). Dichotomized exposures were compared by the odds ratio (OR) and its approximate or exact $95 \%$ confidence interval $(95 \% \mathrm{CI})$, as appropriate. The duration of severe shoulder flexion-abduction was also trichotomized (none; $<10 \%$ of the work cycle; $\geq 10 \%$ of cycle time), and odds ratios were calculated for the 2nd and 3rd tertiles versus none. All the analyses were performed with SAS software (13) except tests of trend and exact $95 \%$ confidence intervals, which were computed using Epi-Info (14).

Potential confounding or effect-modifying variables were considered to include age, length of employment

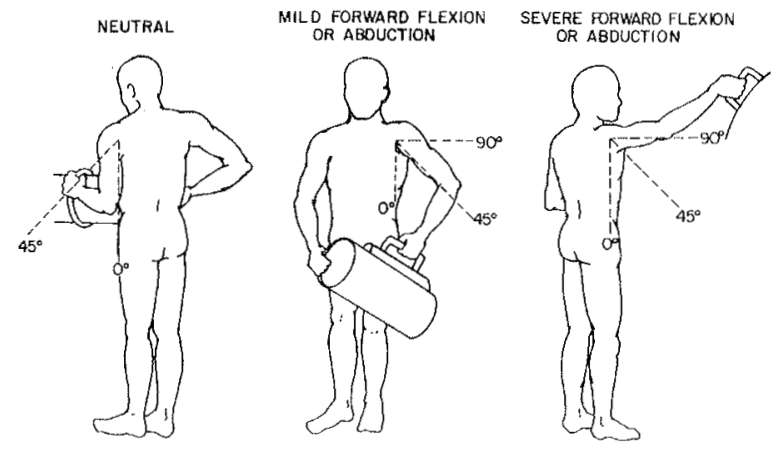

Figure 1. Standard shoulder posture classifications for the analysis of auto assembly jobs.

in the plant or in the same job, past injury to the same shoulder, history of joint disease, and recreational activities. Stratum-specific odds ratios were tested for homogeneity (15) and, if appropriate, the Mantel-Haenszel (M-H) estimator of the common or pooled odds ratio was calculated along with the corresponding $95 \%$ confidence interval (16).

A multivariate logistic regression analysis was used to estimate the odds ratio for shoulder disorders as a function of the duration of severe shoulder flexion-abduction (continuous). (The rank correlation coefficient for the duration and frequency, as motions per minute, of severe flexion was 0.98 for both the left and right sides, so it was not possible to include both or to distinguish between their effects.) Models were fitted by adding other independent variables one at a time to the model with severe flexion. The contribution of each new term to a model was evaluated by the likelihood ratio test (15). No "final" model was selected, as several competing models had about equally high likelihoods and similar odds ratios for the percentage of the cycle in severe shoulder flexion-abduction.

\section{Results}

\section{Frequency and costs of shoulder disorders}

The 104 shoulder problems reported to the plant medical department represented about $7 \%$ of the target work force over a 10 -month period, or an annualized average "incidence" (new or recurrent cases) of 84 cases per 1000 worker-years. This rate varied by production area $(\mathrm{P}<0.0005)$, ranging from a high of 100 in the body department to a low of 20 in the paint department.

Among the 93 workers who reported shoulder disorders and were subsequently interviewed, 33 (35\%) received medication or physical therapy at least once during the 10-month study period (188 treatments). Twenty-nine of these workers reported work absence in 
relation to the current episode of shoulder pain (table 1); $22(24 \%)$ reported at least 1 work restriction since the onset of pain, and 5 workers had been on work restriction for 10 days or more. Difficulty in performing the current or past job was reported by $72 \%$ of them, and 19 (26\%) of them had bid off at least 1 job due to shoulder pain within the 5 years prior to the study. These costs were estimated to average approximately USD 1851 per reported shoulder disorder, excluding workers' compensation and future costs, for a total of USD $172131 \mathrm{ac}-$ crued in 10 months (table 1).

Of the 79 workers with disorders that met the case definition, $48(61 \%)$ workers reported pain on the left side in the interview, and $42(53 \%)$ had pain on the right side. Forty-two cases ( $53 \%$ of 79 ) had at least 1 positive physical examination finding in either shoulder area, and 6 findings were bilateral (table 2). The most prevalent shoulder findings were pain during active external rotation, abduction-elevation, and flexion. The most common

Table 1. Estimated costs associated with 93 cases of shoulder disorder reported to the plant medical department of an automobile assembly plant, Detroit, MI (USA).

\begin{tabular}{|c|c|c|c|}
\hline \multirow[t]{2}{*}{ Ejurce of cost } & $\begin{array}{l}\text { Met study } \\
\text { case criteria }\end{array}$ & \multirow[t]{2}{*}{ Total cost } & \multirow[t]{2}{*}{ Assumptions (see text) } \\
\hline & $\begin{array}{l}\text { Yes No } \\
(\mathbb{N})(N)\end{array}$ & & \\
\hline $\begin{array}{l}\text { In-plant medical visits } \\
\text { and treatments } \mathrm{s}^{\mathrm{a}, \mathrm{b}}\end{array}$ & s 7914 & USD 14050 & $\begin{array}{l}\text { USD } 50 \text { per visit or } \\
\text { treatment }\end{array}$ \\
\hline Employee absences $s^{c_{d} d}$ & d 281 & USD 127905 & $\begin{array}{l}\text { Each } 1 \text {-week absence } \\
\text { required } 1 \text { replacement } \\
\text { worker }\end{array}$ \\
\hline Work restriction ${ }^{c, d}$ & 211 & USD 16192 & $\begin{array}{l}\text { One-half of the work } \\
\text { restrictions required } \\
\text { replacement workers }\end{array}$ \\
\hline $\begin{array}{l}\text { Job change initiated } \\
\text { by employee }{ }^{c_{1}} \text { e }\end{array}$ & $19-$ & USD 13984 & $\begin{array}{l}\text { Each job change } \\
\text { required retraining for } \\
2 \text { workers }\end{array}$ \\
\hline Total & 7914 & USD 172131 & \\
\hline
\end{tabular}

a Data from the records of the plant medical department.

b During a 10-month study period.

- Data from interviews.

d Since onset of pain.

${ }^{\mathrm{e}}$ During the past 5 years.

Table 2. Findings a from the physical examination of the shoulder (active and resisted range of motion maneuvers) among the shoulder cases of the automobile assembly workers with a positive examination.

\begin{tabular}{lrrrrr}
\hline Examination maneuver & \multicolumn{2}{c}{ Left-side $(\mathrm{N}=24)$} & & \multicolumn{2}{c}{ Right-side $(\mathrm{N}=24)$} \\
\cline { 2 - 3 } \cline { 6 - 7 } & $\mathrm{N}$ & $\%$ & & $\mathrm{~N}$ & $\%$ \\
\hline Active abduction or flexion $^{\mathrm{b}}$ & 16 & 67 & & 11 & 46 \\
Any resisted motion $^{\mathrm{c}}$ & 11 & 46 & & 13 & 54 \\
Resisted abduction $^{\mathrm{c}}$ & 8 & 33 & & 9 & 38 \\
\hline
\end{tabular}

a Findings not mutually exclusive.

- Positive finding: pain $>2$ on a scale of $1-5$

- Positive finding: pain $>2$ on a scale of $1-5$; strength $<4$ on a scale of

$1-5$. positive resisted motion was shoulder abduction, implying disorders of the rotator cuff muscles and tendons.

\section{Exposure to physical ergonomic factors}

The jobs of all 203 of the subjects required mild flexion or abduction of at least 1 shoulder. On the average, these workers maintained each shoulder in mild flexion or $a b-$ duction (46 to 90 degrees) for about $25 \%$ of the work cycle. Twelve workers each were required to maintain mild flexion of the left and right shoulders for more than $50 \%$ of the time, with exposure durations as high as $82 \%$ of the cycle.

One hundred and four workers $(51 \%)$ were required to use severe flexion or abduction ( $>90$ degrees) of either shoulder during the job cycle, and $54(27 \%)$ did so with both arms. Some study jobs involved substantial static loading of the shoulder muscles in severe flexionabduction, the duration ranging as high as $66 \%$ of the cycle, and others had high dynamic postural demands, up to 35 posture changes per minute. In general, it appeared that severe flexion-abduction was somewhat more likely to be static on the left side and dynamic on the right side. Although more workers were exposed on the right side (86) than the left (72), the average duration was 8.5 (SD 11.9)\% of the cycle on the left and 7.8 (SD 8.6)\% on the right, while the frequency of changes in shoulder posture averaged 10.0 per minute on the left and 12.6 per minute on the right.

All but 37 subjects, $12(15 \%)$ shoulder cases and 25 (20\%) referents, used a hand-held or larger power tool in their study job. The mean length of the work cycle was slightly shorter for the cases [80.2 (SD 31.0) seconds] than for the referents [88.5 (SD 53.5) seconds] $(\mathrm{P}=0.29)$. The smaller variance in work-cycle length $(\mathrm{F}$ test, $\mathrm{P}=0.0001$ ) for the shoulder cases suggested that they were more likely to work on machine-paced jobs than were the referents.

Thirteen cases (16\%) and 16 referents $(13 \%)$ handled loads of at least 44.5 newtons in their jobs and were analyzed with respect to biomechanical demands. The requirements for shoulder abduction strength were estimated to exceed the capability of $99 \%$ of the male work force of average body size in $27(11 \%)$ of the loaded postures on the right side and $24(10 \%)$ on the left side. Only $6 \%$ (14) of the loaded postures were estimated to result in shoulder rotational forces, on either side, below the capacity of $1 \%$ of the men with average anthropometric values.

\section{Risk factors for shoulder disorders}

The cases spent a slightly higher proportion of the work cycle with either shoulder in severe flexion than did the referents (table 3 ). They also flexed or abducted the shoulder more often per minute than the referents, although the differences were less remarkable for the right 
side. Very similar results were obtained for the subsets of cases with findings in the physical examination and cases with pain on the same side as the exposure.

The risk of having a shoulder disorder was increased from 2- to 3-fold by any severe flexion-abduction, and even more so by exposure for at least $10 \%$ of the job cycle (table 4). The odds ratio for severe flexion of both shoulders at least once per cycle was 4.0 (95\% CI 1.79.4). When only the cases with positive findings in the physical examination were analyzed, the odds ratio point estimates were higher (although less stable) and the exposure-response curves were steeper (table 4).

In the analyses restricted to the cases with pain reported on the same side(s) as the shoulder exposed in the study job, the results differed little or, if anything, were somewhat weaker than those for all the cases. The cases with findings in active abduction or flexion or in any resisted motion had higher odds ratios, although the confidence intervals were very wide because of the small numbers.

There was no significant difference between the cases and referents in the frequency of handling loads of at least 44.5 newtons (OR 1.3, 95\% CI $0.6-3.1$, for all shoulder cases; OR 1.1, 95\% CI 0.4-3.1, for physical examination cases) nor in the estimated peak biomechanical torques at either shoulder (Wilcoxon $\mathrm{P}$-value $=0.18$ for flexion, $\mathrm{P}=0.61$ for adduction, $\mathrm{P}=0.27$ for abduction).

These associations were not substantially affected by exclusion of the 4 female workers nor by stratification by age, seniority, systemic disease, injury history, sports and hobbies, or job analysis on a proxy worker. Nonhomogeneous point estimates were found after stratification for use of power tools. Among the 37 workers not using power tools, the association with severe flexion-abduction of the shoulder was about 6 times higher than among the tool users.

As estimated by a multivariate logistic regression, the risk of shoulder disorder increased by 1.4 (95\% CI 1.11.8) for each increment of $10 \%$ of the work cycle with severe flexion-abduction. Work with a power tool in the study job also increased the risk, but the estimate of effect was unstable (OR 2.0,95\% CI 0.6-7.0). Use of the job-analysis data obtained for a proxy worker was associated with case-referent status, although in the opposite direction from that expected (OR 3.2,95\% CI 1.0-10.0). In other models, a history of acute shoulder injury was a risk factor (odds ratio ranged from about 8 to 15 among the models, all P-values $\leq 0.004$ ) but had little or no effect on the point estimates for any occupational exposures.

\section{Discussion}

In this study of active workers in an automotive assembly plant, the annualized incidence of shoulder disorders reported to the plant medical department was 8.4 per 100 worker-years, or about two-thirds as high as the annual

Table 3. Shoulder postures required by the jobs of the persons with shoulder problems and their referents - mean exposures and nonparametric P-values.

\begin{tabular}{|c|c|c|c|c|c|c|c|c|c|c|c|}
\hline & \multicolumn{11}{|c|}{ Exposure } \\
\hline & \multicolumn{5}{|c|}{ Duration (\% cycle) } & \multicolumn{6}{|c|}{ Frequency (changes/minute) } \\
\hline & \multicolumn{2}{|c|}{ Mild flexion } & \multicolumn{3}{|c|}{ Severe flexion } & \multicolumn{2}{|c|}{ Mild flexion } & \multicolumn{2}{|c|}{ Severe flexion } & \multicolumn{2}{|c|}{ Any motion } \\
\hline & Left & Right & Left & Right & Either side & Left & Right & Left & Right & Left & Right \\
\hline Shoulder cases $(\mathrm{N}=79)$ & 24.7 & 28.2 & 5.3 & 4.7 & 10.0 & 4.9 & 6.0 & 1.0 & 1.1 & 11.5 & 13.6 \\
\hline Referents $(\mathrm{N}=124)$ & 22.3 & 27.0 & 1.6 & 2.4 & 3.9 & 4.0 & 5.4 & 0.4 & 0.6 & 9.0 & 12.1 \\
\hline$P$-value a & 0.20 & 0.63 & 0.0002 & 0.01 & 0.003 & 0.007 & 0.07 & 0.0001 & 0.009 & 0.0007 & 0.02 \\
\hline
\end{tabular}

a From the Wilcoxon rank sum test.

Table 4. Shoulder disorders and exposure to severe shoulder flexion or abduction ${ }^{\mathrm{a}}$ - odds ratios and $95 \%$ confidence intervals for the cases versus the referents.

\begin{tabular}{|c|c|c|c|c|c|c|c|c|c|c|}
\hline & \multicolumn{4}{|c|}{ Shoulder disorders } & \multicolumn{6}{|c|}{ Exposure to severe shoulder flexion or abduction " } \\
\hline & \multicolumn{2}{|c|}{ Left (yes/no) } & \multicolumn{2}{|c|}{ Right (yes/no) } & \multicolumn{3}{|c|}{ Left } & \multicolumn{3}{|c|}{ Right , } \\
\hline & $\mathrm{OR}$ & $95 \% \mathrm{Cl}$ & OR & $95 \% \mathrm{Cl}$ & $>0-<10 \%$ & $\geq 10 \%^{\mathrm{b}}$ & P-value & $>0-<10 \%$ & $\geq 10 \%^{b}$ & P-value \\
\hline All cases $(N=79)$ & 2.9 & $1.6-5.4$ & 1.9 & $1.1-3.4$ & 2.5 & 5.1 & 0.0001 & 1.7 & 2.8 & 0.02 \\
\hline $\begin{array}{l}\text { Cases with physical } \\
\text { examination findings ( } N=42)\end{array}$ & 3.2 & $1.5-6.5$ & 2.3 & $1.2-4.8$ & 2.5 & 6.1 & 0.0004 & 2.0 & 3.9 & 0.007 \\
\hline
\end{tabular}

a Occupational exposure to shoulder flexion or abduction of at least 90 degrees, at least once per minute, on the specified side.

v values are the odds ratio point estimates.

c P-value from the test of linear trend (chi-square with 1 degree of freedom). 
incidence of back disorders (12\%) estimated for the same target population (8). This ratio is consistent with that found by at least 1 other study in heavy manufacturing (17). The reported shoulder disorders were both recurrent and chronic and associated with substantial costs of medical treatment, lost time from work, work restrictions, and bidding off jobs perceived as difficult or as aggravating shoulder pain. These cost estimates were necessarily incomplete (18), but nevertheless they were about 3 times higher than the median cost per case of "compensable upper-extremity cumulative trauma disorder" in Michigan in 1989 (19).

The results of this study suggest a relationship between shoulder disorders and both postural stress and power tool use. The postural demands, both static and dynamic, were substantial in some of the study jobs. Severe forward flexion or abduction of the left shoulder was clearly a risk factor for shoulder disorders, while the evidence was equivocal for right-sided postural stress. The results for cases with physical findings in the examination were similar to or slightly stronger than those for all the cases who had sought medical attention.

Occupational use of power tools interacted strongly with elevated shoulder posture in these data. In another study of automobile assembly lines, a higher duration and frequency of holding and using power tools was the main distinguishing characteristic of jobs with high versus low rates of forearm-hand symptoms (20). Vibration transmitted by hand-held tools has been shown to be a strong risk factor for shoulder tendinitis $(21,22)$. In these data, tool use was likely on the causal pathway, since shoulder flexion often occurred while a tool was operated, which may explain the fact that the additional effect of posture was smaller among tool users than among nonusers.

The distribution of exposures in the study population limited our ability to clarify further the relationship between postural stress, power tool use, and shoulder disorders. Most of the subjects used power tools in their jobs. There were relatively few with low exposure to nonneutral postures; all of the jobs involved mild flexion-abduction (included angle of 46 to 90 degrees) of at least 1 shoulder. On the other hand, only a small number of jobs required severe flexion for a prolonged duration (at least $10 \%$ of the cycle). Thus, although the goal had been to compare the effects of severe flexion-abduction with no postural stress, instead the exposure contrast available for study was that of short periods of severe flexion plus prolonged periods of mild flexion versus prolonged periods of mild flexion only. Because of the correlation between shoulder flexion duration and frequency, it was not possible to distinguish the effects of static and dynamic postural stress in these jobs.

Only the cases who sought attention at the plant medical department were eligible for study. We attempted to confirm the clinical importance of the cases, and to exclude referents with shoulder problems, by imposing the additional criteria of pain reported in the interview and findings of a physical examination. The magnitude of the unreported morbidity can be estimated from the 134 of the $259(52 \%)$ potential referents who had evidence of shoulder, neck, or back problems. Thus the study probably underestimated the total frequency and cost of shoulder disorders in the study population. It is also possible that some cases or referents had had shoulder problems prior to the period of data collection. However, neither of these possible sources of misclassification represents a likely alternative explanation for the associations with occupational job demands.

The screening examination used in this study was not designed to generate specific clinical diagnoses. Nevertheless the finding that resisted abduction was the most frequent positive resisted maneuver suggests that rotator cuff disorders were common in this population. The physical findings also provide a measure of severity of the shoulder disorders. Fifty-three percent of the cases had positive findings in the physical examination, while $61 \%$ had taken some time off because of their shoulder disorder. Since the physical examination took place several weeks after the workers' medical department visits (median 28 days), it is possible that some cases may have had positive physical findings earlier which had resolved by the time of the examination.

\section{Side-specific associations}

The stronger association with the postural demands of work on the left side than on the right is biologically implausible and suggests that the relationship between shoulder disorders and exposure to the right shoulder was either biased by misclassification or confounding or was strongly modified by other factors.

One source of misclassification may have been random error in the data collection, especially in the estimation of exposure. For example, since exposure was characterized after the onset of pain for the cases, by the time of being videotaped, a case could have changed hands from that used to perform the job prior to pain onset. Such occurrences would lead to misclassification of the side exposed in the job analyses; however, it does not seem likely that the resulting bias would be stronger on one side than on the other.

It should also be noted that postures were recorded within a range, rather than the precise angle of flexion or abduction at each moment being estimated. Thus there may have been intrastratum confounding if the actual degree of arm elevation within a given range tended to be greater on one side than on the other. This possibility could have caused an artifact of apparently greater effect of postural stress on the left side than on the right. 
In addition, the postural stress in the study jobs appeared to be slightly more static in nature for the left shoulder and more dynamic for the right shoulder. If static or low velocity effort is more injurious than dynamic movements are, a theory for which there is physiological evidence (23), and, especially, if the static loading was applied to the side that was weaker for most subjects, then the results obtained may be explained. Unfortunately, as already noted, the distribution of exposures in the study population did not permit direct comparison of the effects of static and dynamic effort.

Data were not collected on the preferred hands of the study subjects, but it seems unlikely that hand preference could explain the results. Approximately $90 \%$ of the total population was right-handed, and the upper extremity strength differential between sides was only $10 \%$ or less, on the average (24). In the laboratory, strength capability is not associated with short-term fatigue and discomfort produced by elevated shoulder posture (4). However, another aspect of functional capacity, such as better coordination on the dominant side, may have exerted a protective effect; this possibility deserves exploration in future research.

The exposures had to be estimated from proxy subjects for cases more often than for referents. Since we stratified according to whether or not an alternate worker was filmed for the job of the study subject, we controlled for the possibilities that a job was filmed on the opposite side of the assembly line from that indicated by the study subject or that an alternate worker used the other hand from that used by the study subject. The pooled results produced a slightly higher odds ratio for right-side exposure than the crude analysis did, but the effect was still weaker than for the left side.

Thus we have been unable to identify a source of misclassification likely to explain the observed difference between the effects of right and left shoulder postures.

We attempted to examine the difference between sides by analyzing only cases with pain history on the same side as the exposed shoulder. Although this could be expected to produce greater specificity, the results were, surprisingly, not markedly different from those reported here. It has been posited that postural stress may affect the muscles in both the working and the nonworking arms. For example, Karlquist et al (25) found increased trapezius activity in electromyography on both sides when only the right hand was using a computer mouse or track ball, an effect that could be due to contralateral muscle activation or to neck flexion (26).

Manual materials handling has been shown to increase the risk of shoulder disorders $(17,22,27,28)$. In this study, only $14 \%$ of the subjects handled objects weighing at least 44.5 newtons. We used biomechanical modeling to estimate the resultant shoulder loads; the values were relatively low, on the average, and similar between the right and left sides and between the cases and referents. Other forces were not estimated by our methods. We observed in the plant that, when both arms were elevated, the nature of the stress on the 2 arms could be quite different. For example, in jobs requiring the operation of a power tool above shoulder height, the left hand was often used to hold a part in position while the right hand was used to operate the tool. Data were not collected on which hand used the tool nor on the vibration, rotational torques, and reaction forces characteristic of these tools. The direction of the force applied through the tool is also relevant to an understanding of the internal muscle and joint forces; arm posture alone is insufficient to estimate the resulting forces $(10,29)$. The use of a power tool must therefore be considered in this study as a proxy variable for these other, more specific factors and may therefore explain at least part of the difference found between right- and left-side exposures.

\section{Interpretation of study results}

Nonoccupational risk factors that have been demonstrated or postulated for shoulder disorders include female gender, younger or older age, immigrant status, smoking, short stature, being overweight, recreational activities, job satisfaction, and mental or emotional stress (17, $27,28,30-34)$. In this study, socioeconomic status and psychosocial strain were not measured but were unlikely to vary greatly within the population of blue-collar assembly workers. Smoking was not assessed. Data on age, gender, medical history, prior injuries, and sports, hobbies or second jobs were obtained in an interview, and their effects were examined in stratified and multivariate analyses. Only history of acute injury to the shoulder was significantly associated with the odds of being a case, but it did not change the point estimate for the effects of exposure, and only a few workers had sustained previous injuries. Thus, within the limitations of this study, the relationship of shoulder disorders to postural stress was not explained by nonoccupational factors. The lack of association with time-related covariates, such as age and seniority, may be a result of self-selection of shoulder cases out of the work force, sometimes known as the "healthy worker effect" $(35,36)$.

The published literature on shoulder disorders has demonstrated a relationship with work pace and repetitive arm movements on the job, and with work postures requiring forward flexion or abduction of the shoulder $(3,5,6)$. Among the few studies with objective measures of both exposure and outcome, Kilbom and her colleagues found the daily duration and frequency of shoulder elevation to be associated both cross-sectionally and longitudinally with neck-shoulder disorders $(30,31)$, and 3 other investigations provided quantitative exposure-response data on shoulder disorders in relation to ergonomic job features in manufacturing and fish processing (32, 
37, 38). An additional 6 studies have reported associations between shoulder disorders in an examination and combined occupational exposures that include postural strain $(28,33,39-42)$. Overall, the results of these studies are consistent with our findings. Thus this investigation adds to the small number of reports in which shoulder disorders were assessed by physical examination and objective, quantitative exposure data were obtained on shoulder postures. It contributes some information on the duration and intensity of exposure that may be harmful, specifically, that an increased risk was associated with the arm elevated above 90 degrees during a relatively small fraction of the workshift.

Physical load on the shoulder appeared to explain a large proportion of the shoulder disorders in this automobile assembly plant. Recommendations were made to the company and the union that, for jobs with high postural demands on the shoulder, redesign of the workstation layout and job task sequences may eliminate or reduce such stressors. Such redesign could be expected to reduce both the number of workers reporting to the medical department with shoulder disorders and related costs due to such factors as work restrictions, health-related job transfers, and lost time. Despite the apparent discrepancy between the contribution of right and left postures to shoulder disorders, we believe that, overall, these data support the conclusion that shoulder flexion or abduction above 90 degrees, especially for $10 \%$ or more of the work cycle, is predictive of chronic or recurrent shoulder disorders. Future research on occupational risk factors for musculoskeletal shoulder disorders should explore the effects of power tool characteristics in greater detail and should identify suitable populations and exposure distributions in order to examine further the interaction among postural stress, biomechanical loading, and power tool characteristics.

\section{Acknowledgments}

This study was sponsored by the Body and Assembly Operations Division of the Ford Motor Company. The authors gratefully acknowledge the contributions of the following persons in the data collection and analysis: $\mathrm{MJ}$ Catterall, R Ermak, T Galasso, L Harner, S Lee, P McEachern, D Radson, M Scarr, J Steele, C Woolley, A Wright, and W Butler.

Previous versions of the paper were presented at the V International Symposium on Epidemiology in Occupational Health, Los Angeles, CA, September 1986, and the International Conference on Musculoskeletal Disorders at Work, The Robens Institute, University of Surrey, Guildford, England, April 1987.

\section{References}

1. Anderson JAD. Shoulder pain and tension neck and their relation to work. Scand J Work Environ Health 1984;10:435 42.

2. Hagberg M. Occupational musculoskeletal stress and disorders of the neck and shoulder: a review of possible pathophys1ology. Int Arch Occup Environ Health 1984;53:269-78.

3. Winkel J, Westgaard R. Occupational and individual risk factors for shoulder-neck complaints, part II: the scientific bases (literature review) for the guide. Int J Ind Ergon 1992; 10:85-104.

4. Wiker SF, Chaffin DB, Langolf GD. Shoulder posture and localized muscle fatigue and discomfort. Ergonomics 1990;32:211-37.

5. Hagberg M, Wegman DH. Prevalence rates and odds ratios of shoulder-neck diseases in different occupational groups. Br J Ind Med 1987;44:602-10.

6. Bernard BP, editor. Musculoskeletal disorders and workplace factors: a critical review of epidemiologic evidence for workrelated musculoskeletal disorders of the neck, upper extremity, and low back. Cincinnati $(\mathrm{OH})$ : Department of Health and Human Services, National Institute for Occupational Safety and Health (NIOSH) 1997. DHHS (NIOSH) publication no 97-141.

7. Silverstein BA, Fine LJ. Evaluation of upper extremity and low back cumulative trauma disorders: a screening manual. Ann Arbor (MI): Department of Environmental and Industrial Health, School of Public Health, University of Michigan, 1984.

8. Punnett L, Fine LJ, Keyserling WM, Herrin GD, Chaffin DB. Back disorders and nonneutral trunk postures of automobile assembly workers. Scand J Work Environ Health 1991; $17: 337-46$.

9. Keyserling WM. Postural analysis of the trunk and shoulders in simulated real time. Ergonomics 1986;29:569-83.

10. Chaffin DB, Andersson GBJ, Martin BJ. Occupational biomechanics. 3rd ed. New York (NY): John Wiley \& Sons, 1999:chapter 6.

11. Fleiss JL. Statistical methods for rates and proportions, second edition. New York (NY): John Wiley \& Sons, 1981.

12. Wilcoxon F. Individual comparisons by ranking methods. Biomet Bull 1945;1:80.

13. Statistical Analysis System Institute Inc. SAS user's guides, version 5.15. Cary (NC): SAS Institute Inc, 1985.

14. Dean AG, Dean JA, Coulombier D, Brendel AH, Dicker RC, Sullivan K, et al. Epi Info 6, version 6: work processing, database, and statistics program for public health on IBMcompatible mictrocomputers. Atlanta (GA): Centers for Disease Control and Prevention; Geneva: World Health Organization; 1995.

15. Breslow NE, Day NE. Statistical methods in cancer research; vol I (The analysis of case-control studies). Lyon: International Agency for Research on Cancer, 1980.

16. Mantel N, Haenszel W. Statistical aspects of the analysis of data from retrospective studies of disease. JNCI 1959; $22: 719-48$.

17. Kvarnström S. Occurrence of musculoskeletal disorders in a manufacturing industry, with special attention to occupational shoulder disorders. Scand J Rehabil Med 1983;suppl 8:1114.

18. Punnett L. The costs of work-related musculoskeletal disorders in automotive manufacturing. $N$ Solutions. In press. 
19. Webster BS, Snook SH. The cost of compensable upper extremity cumulative trauma disorders. J Occup Med 1994; 36:713-7.

20. Fransson-Hall C, Byström S, Kilbom $\AA$. Characteristics of forearm-hand exposure in relation to symptoms among automobile assembly line workers. Am J Ind Med 1996;29:1522.

21. Dimberg L, Olafsson A, Stefansson E, Aagaard H, Oden A, Andersson $\mathrm{G}$, et al. The correlation between work environment and the occurrence of cervicobrachial symptoms. J Occup Med 1989;31:447-53.

22. Stenlund B, Goldie I, Hagberg M, Hogstedt C. Shoulder tendinitis and its relation to heavy manual work and exposure to vibration. Scand J Work Environ Health 1993;19:43-9.

23. Sjøgaard G, Søgaard K. Muscle injury in repetitive motion disorders. Clin Orthop 1998;351:21-31.

24. Van Cott HP, Kinkade RG. Human engineering guide to equipment design. Revised edition. Washington (DC): US Government Printing Office, 1972.

25. Karlqvist L, Bernmark E, Ekenvall L, Hagberg M, Isaksson A, Rostö T. Computer mouse and track-ball operation: Similarities and differences in posture, muscular load and perceived exertion. Int J Ind Ergon 1999;23(3):157—69.

26. Schüldt $K$, Harms-Ringdahl K. Activity levels during isometric test contractions of neck and shoulder muscles. Scand J Rehab Med 1988;20:117-27.

27. Holmström EB, Lindell J, Moritz U. Low back and neck/ shoulder pain in construction workers: occupational workload and psychosocial risk factors, part 2: relationship to neck and shoulder pain. Spine 1992;672-7.

28. Dimberg L, Olafsson A, Stefansson E, Aagaard H, Oden A, Andersson G, et al. Sickness absenteeism in an engineering industry - an analysis with special reference to absence for neck and upper extremity symptoms. Scand J Soc Med 1989;17:77-84.

29. Karlsson D, Peterson B. Towards a model for force predictions in the human shoulder. J Biomech 1992;25(2):189_99.

30. Kilbom $\AA$, Persson J, Jonsson BG. Disorders of the cervicobrachial region among female workers in the electronics industry. Int J Ind Ergon 1986;1:37- 47.

31. Jonsson BG, Persson J, Kilbom $\AA$. Disorders of the cervicobrachial region among female workers in the electronics in- dustry: a two-year follow up. Int J Ind Ergon 1988;3:1-12.

32. Ohlsson K, Attewell RG, Paisson B, Karlsson B, Balogh I, Johnsson B, et al. Repetitive industrial work and neck and upper limb disorders in females. Am J Ind Med 1995;27:731-47.

33. Ohlsson K, Hansson G, Balogh I, Stromberg U, Paisson B, Nordander C, et al. Disorders of the neck and upper limbs in women in the fish processing industry. Occup Environ Med $1994 ; 51: 826-32$

34. Ekberg K, Björkqvist B, Malm P, Bjerre-Kiely B, Karlsson $\mathrm{M}$, Axelson O. Case-control study of risk factors for disease in the neck and shoulder area. Occup Environ Med 1994; 51:262-6.

35. Punnett L. Adjusting for the healthy worker selection effect in cross-sectional studies. Int J Epidemiol 1996;25:1068 - 75, published erratum appears in Epidemiology 1997;26:914.

36. Park RM, Krebs JM, Mirer FE. Occupational disease surveillance using disability insurance at an automotive stamping and assembly complex. J Occup Env Med 1996;38:1111-23.

37. Bjelle A, Hagberg M, Michaelson G. Work-related shoulderneck complaints in industry: A pilot study. Br J Rheum 1987; 26:365-9.

38. Chiang H-C, Ko Y-C, Chen S-S, Yu H-S, Wu T-N, Chang P$Y$. Prevalence of shoulder and upper-limb disorders among workers in the fish-processing industry. Scand J Work Environ Health 1993;19:126-31.

39. Törner M, Zetterberg C, Andén U, Hansson T, Lindell V. Workload and musculoskeletal problems: a comparison between welders and office clerks (with reference also to fishermen). Ergonomics 1991;34:1179-96.

40. Westgaard RH, Åaras A. The effect of improved workplace design on the development of work-related musculo-skeletal illnesses. Appl Ergon 1985;15:185—96.

41. Punnett L. Ergonomic stressors and upper extremity disorders in vehicle manufacturing: cross-sectional exposure-response trends. Occup Environ Med 1998;55:414-20.

42. Frost $P$, Andersen JH. Shoulder impingement syndrome in relation to shoulder intensive work. Occup Environ Med 1999;56:494-8.

Received for publication: 4 May 1999 